\title{
Dominant factors for very-high-cycle fatigue of high-strength steels and a new design method for components
}

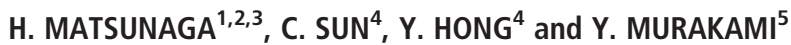 \\ ${ }^{1}$ Department of Mechanical Engineering, Kyushu University, Fukuoka, Japan, ${ }^{2}$ Research Center for Hydrogen Industrial Use and Storage \\ (HYDROGENIUS), Kyushu University, Fukuoka, Japan, ${ }^{3}$ International Institute for Carbon-Neutral Energy Research (I2CNER), Kyushu University, \\ Fukuoka, Japan, ${ }^{4}$ LNM, Institute of Mechanics, Chinese Academy of Sciences, Beijing, China, ${ }^{5}$ Professor Emeritus, Kyushu University, Fukuoka, Japan
}

Received Date: 21 March 2015; Accepted Date: 6 fune 2015; Published Online: 2015

A B S TRACT Dominant factors affecting fatigue failure from non-metallic inclusions in the very-highcycle fatigue (VHCF) regime are reviewed, and the mechanism for the disappearance of the conventional fatigue limit is discussed. Specifically, this paper focuses on the following: (i) the crucial role of internal hydrogen trapped by non-metallic inclusions for the growth of the optically dark area (around the non-metallic inclusion at fracture origin), (ii) the behaviour of the crack growth from a non-metallic inclusion as a small crack and (iii) the statistical aspects of the VHCF strength, in consideration of the maximum inclusion size, using statistics of extremes. In addition, on the basis of the aforementioned findings, a new fatigue design method is proposed for the VHCF regime. The design method gives the allowable stress, $\sigma_{\text {allowable }}$, for a determined design life, $N_{\mathrm{fD}}$, as the lower bound of scatter of fatigue strength, which depends on the amount of components produced.

Keywords bearing steel; non-metallic inclusion; small crack; the $\sqrt{\text { area }}$ parameter model; very-high-cycle fatigue.

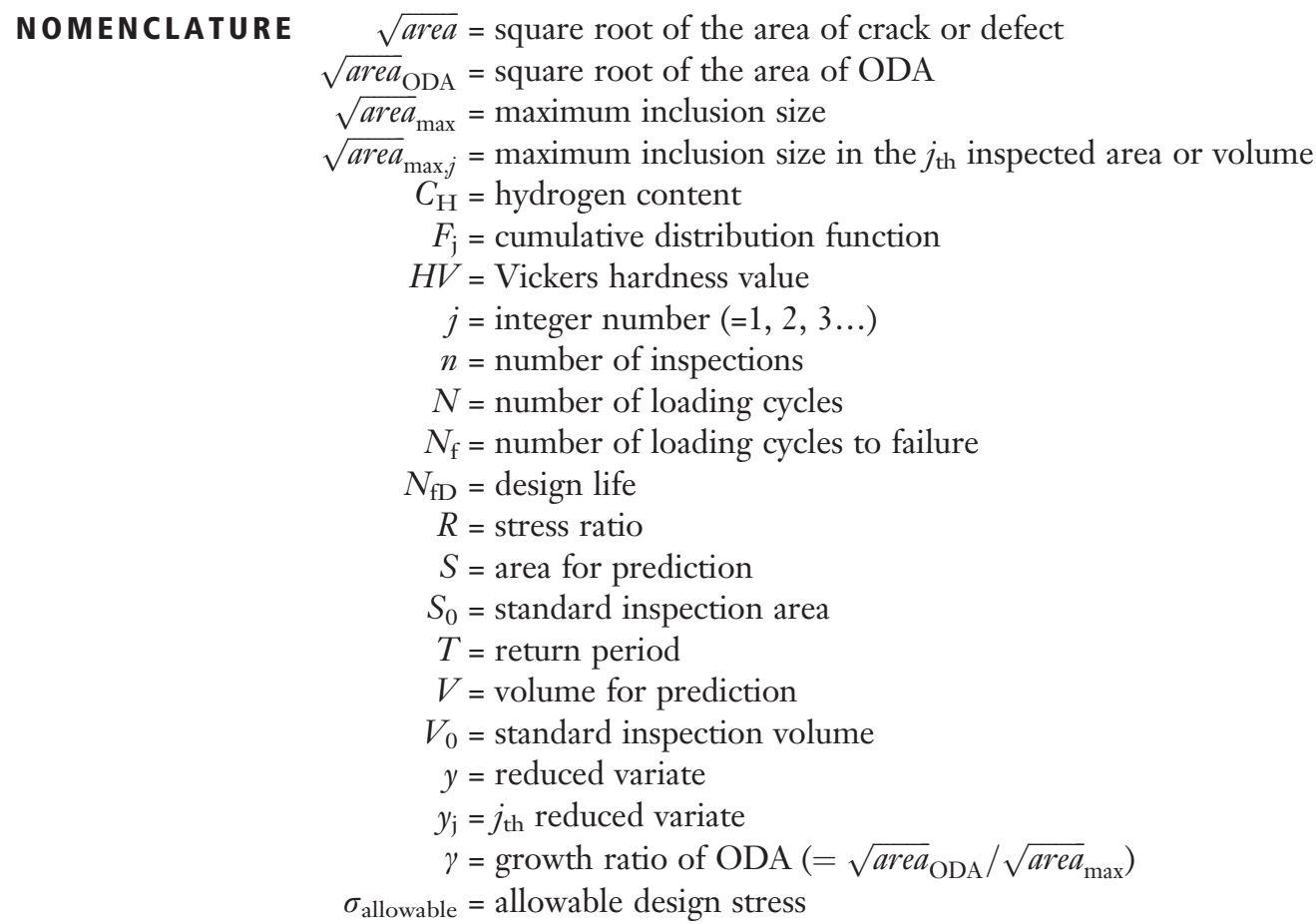




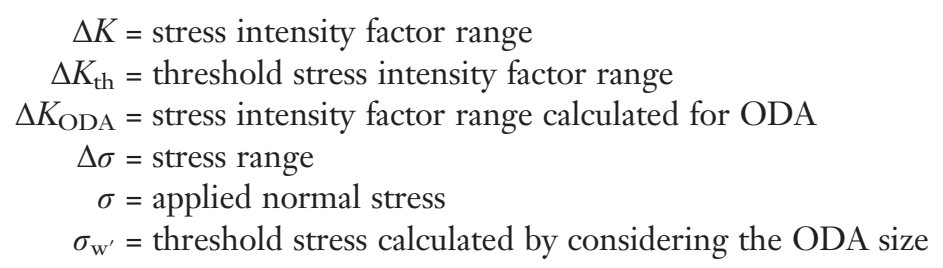

\section{INTRODUCTION}

The disappearance of the conventional fatigue limit (Fig. 1), as has been defined by fatigue testing up to $10^{7}$ cycles, is a matter of great concern for many researchers. ${ }^{1-26}$ A topic of intense debate has been the mechanism leading to fatigue fracture of high-strength steels in the very-highcycle fatigue (VHCF) regime, most of which originates from the non-metallic inclusions at the sub-surface. In the late $1990 \mathrm{~s}$, Murakami et al. ${ }^{1-4}$ identified the presence of a particular morphology, that is, an optically dark area (ODA), which surrounds the inclusion at fracture origin. They presumed that the formation of the ODA is influenced by hydrogen trapped by inclusions. ${ }^{5-8}$ According to detailed observations by Murakami et al. the growth of the ODA is not due to the ordinary cycle-by-cycle fatigue mechanisms, but due to the very slow, non-cycle-by-cycle crack growth caused by a synergistic effect with cyclic stress and hydrogen trapped by inclusions. ${ }^{5-8}$ The mechanism suggests that when evaluating the fatigue strength of highstrength steels, the following factors should be considered:

(i) the growth rule of the ODA with the assistance of internal hydrogen;

(ii) the difference between small cracks and large cracks, with regard to the threshold stress intensity factor range, $\Delta K_{\text {th }}$; (iii) the statistical aspect of fatigue strength, as influenced by inclusion size.

In the present paper, the factors which affect the fatigue failure of high-strength steels in the VHCF regime are reviewed, and the mechanism leading to the non-existence of the conventional fatigue limit is later discussed. In addition, a new fatigue design method is proposed for the VHCF regime. The new design method gives the allowable

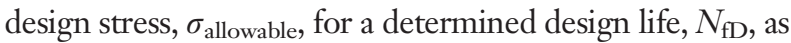
the lower bound of scatter of fatigue strength depends on the amount of components produced.

\section{MATERIALS}

The elimination of the conventional fatigue limit in the VHCF regime has been observed for various high-strength steels, with high hardness values ( $H V=500-700$ or higher), for example, Cr-Mo steels, bearing steels and spring steels. ${ }^{1-22}$

In the present paper, the data from a Cr-Mo steel (JISSCM435) $)^{1-5,7}$ and two bearing steels (JIS-SUJ2 and GCr15 $)^{6,9,10}$ are reviewed. Table 1 presents the material data and test methods. In order to reveal the effects of hydrogen trapped in materials, the data for specimens with different hydrogen content are compared. The loading types are tensioncompression, ${ }^{1-7}$ rotating bending ${ }^{17}$ and ultrasonic testing, ${ }^{9}$

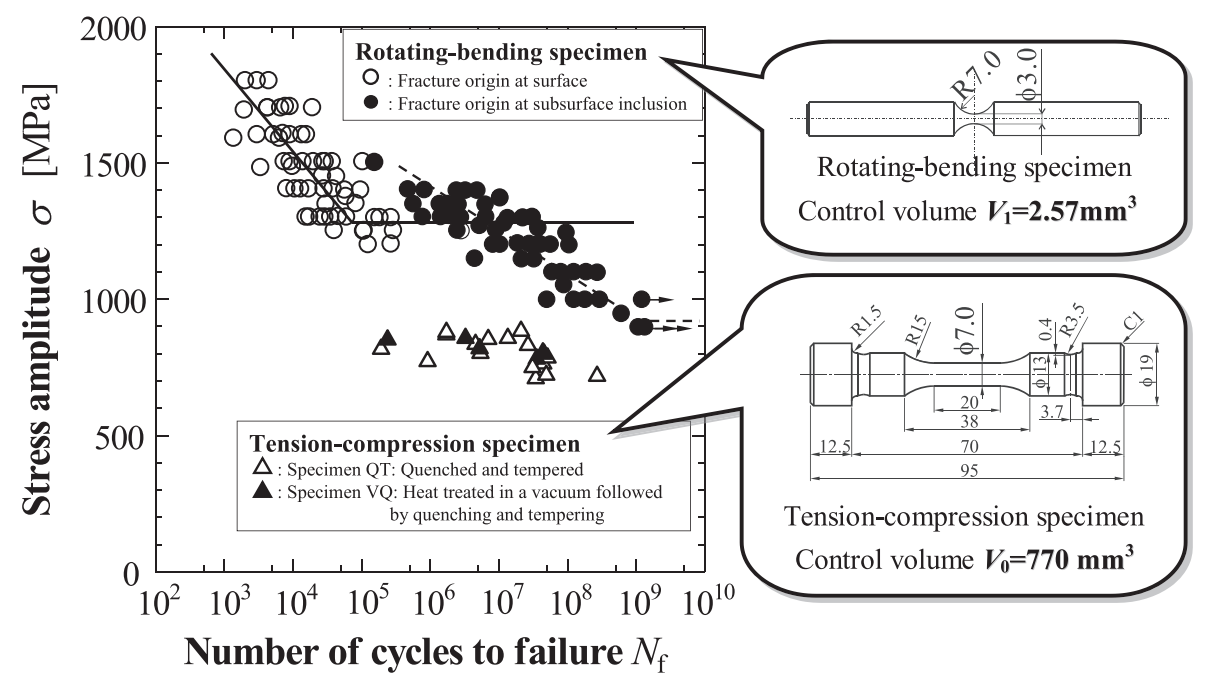

Fig. 1 Size effect in VHCF property — comparison of $S-N$ data for rotating-bending [17] and tension-compression [6] specimens of JIS-SUJ2. 
Table 1 Material data and test methods $[3,6,9,17]$

\begin{tabular}{|c|c|c|c|c|c|c|c|}
\hline Materials & Material types & Heat treatments & $\begin{array}{l}\text { Vickers } \\
\text { Hardness } \\
\quad H V\end{array}$ & $\begin{array}{l}\text { Hydrogen } \\
\text { content } \\
\text { (mass ppm) }\end{array}$ & $\begin{array}{c}\text { Test } \\
\text { method }\end{array}$ & $\begin{array}{l}\text { Specimen } \\
\text { diameter } \\
(\mathrm{mm})\end{array}$ & $\begin{array}{l}\text { Test } \\
\text { frequency } \\
\quad(\mathrm{Hz})\end{array}$ \\
\hline \multirow[t]{2}{*}{ Cr-Mo steel } & $\begin{array}{l}\text { JIS-SCM435, } \\
(\mathrm{QT})[3]\end{array}$ & $\begin{array}{l}\text { Quenching: } 850^{\circ} \mathrm{C} \\
\text { (Rx gas); tempering: } \\
170^{\circ} \mathrm{C} \text {, carbon-nitrided }\end{array}$ & 561 & $0.7-0.9$ & $\begin{array}{l}\text { Tension- } \\
\text { compression }\end{array}$ & 7 & $30-100$ \\
\hline & $\begin{array}{l}\text { JIS-SCM435 } \\
\text { (VQ) [3] }\end{array}$ & $\begin{array}{l}\text { Quenching: } 850^{\circ} \mathrm{C} \\
\text { (vacuum); tempering: } \\
170^{\circ} \mathrm{C} \text {, carbon-nitrided }\end{array}$ & 586 & $\sim 0.01$ & $\begin{array}{l}\text { Tension- } \\
\text { compression }\end{array}$ & 7 & $30-100$ \\
\hline \multirow[t]{3}{*}{ Bearing steels } & $\begin{array}{l}\text { JIS SUJ2 QT } \\
\text { and VQ [6] }\end{array}$ & $\begin{array}{l}\text { Quenching: } 840^{\circ} \mathrm{C} \\
\text { (Rx gas or vacuum); } \\
\text { tempering: } 180^{\circ} \mathrm{C}\end{array}$ & $\sim 700$ & 0.8 & $\begin{array}{l}\text { Tension- } \\
\text { compression }\end{array}$ & 7 & $1-50$ \\
\hline & JIS SUJ2 [17] & $\begin{array}{l}\text { Quenching: } 835^{\circ} \mathrm{C} \text {; } \\
\text { tempering: } 180^{\circ} \mathrm{C}\end{array}$ & 778 & $\begin{array}{l}\text { Data not } \\
\text { available }\end{array}$ & $\begin{array}{l}\text { Rotating- } \\
\text { bending }\end{array}$ & 3 & 52.5 \\
\hline & GCr15 VQ [9] & $\begin{array}{l}\text { Quenching: } 845^{\circ} \mathrm{C} \\
\text { (vacuum); tempering: } \\
300^{\circ} \mathrm{C}\end{array}$ & 741 & 0.12 & Ultrasonic & 3 & 20000 \\
\hline
\end{tabular}

which were operated at frequencies of $1-50,52.5$ and $20000 \mathrm{~Hz}$, respectively. All tests were performed at stress ratio, $R=-1$. Details about the materials and the experimental procedures were reported in the literature. ${ }^{1-7,9,17}$

\section{FACTORS AFFECTING VERY-HIGH-CYCLE FATIGUE}

\section{Inclusions, optically dark area and hydrogen at frac- ture origin}

Fatigue fracture origins of high-strength steels failed in the VHCF regime exhibit a common particular morphology. The unique characteristics can be summarized as follows:

1 In most cases, specimens exhibit a 'fish-eye' pattern, where the fatigue crack originates from a sub-surface, non-metallic inclusion. The types of inclusions include $\mathrm{Al}_{2} \mathrm{O}_{3}, \mathrm{Al}_{2} \mathrm{O}_{3} \cdot(\mathrm{CaO})_{\mathrm{x}}$, TiN, $\mathrm{MnS}$, and so on. ${ }^{2-6,27}$

2 In the region of fracture origin, a dark area can be observed with an optical microscope in the vicinity of the inclusion. The dark area is labelled ODA. ${ }^{1,2}$ Figures 2 and 3 present optical micrographs of the fracture origins in JIS-SCM435 specimens, QT (hydrogen content: $C_{\mathrm{H}}=0.7-0.9$ mass ppm) and VQ $\left(C_{\mathrm{H}}=\sim 0.01\right.$ mass ppm). ${ }^{5}$ The size of the ODA increases with an increase in fatigue life, $N_{\mathrm{f}}$. However, the ODA is not found at fracture origin in the case of a short fatigue life (e.g. Fig. 2(a)).

3 The specimens containing low hydrogen content exhibit a small ODA. A comparison of Figs. 2 and 3 shows that the ODAs in the VQ specimens $\left(C_{\mathrm{H}}=\sim 0.01\right.$ mass $\left.\mathrm{ppm}\right)$ are much smaller than those in the QT specimens $\left(C_{\mathrm{H}}=0.7-0.9\right.$ mass ppm $)$, at an

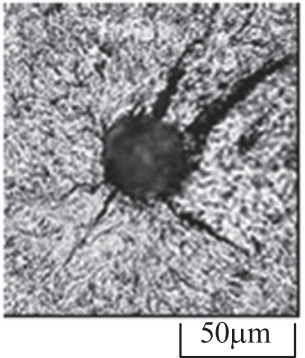

(a) $\sigma=833(\mathrm{MPa})$

$$
\begin{gathered}
N_{f}=3.82 \times 10^{5} \\
\sqrt{\text { area }}=33(\mu \mathrm{m}) \\
\sqrt{\text { area }} \text { ODA }=33(\mu \mathrm{m})
\end{gathered}
$$

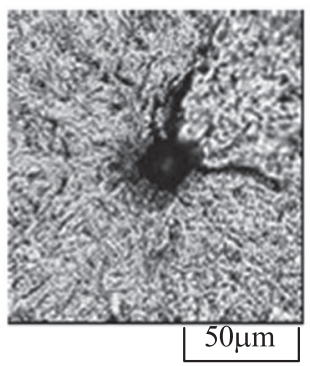

(b) $\sigma=781(\mathrm{MPa})$

$$
N_{f}=6.54 \times 10^{6}
$$$$
\sqrt{\text { area }}=19(\mu \mathrm{m})
$$$$
\sqrt{\text { area }}_{\text {ODA }}=33(\mu \mathrm{m})
$$

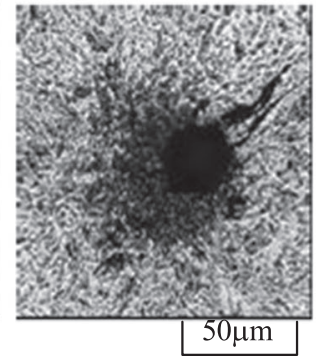

(c) $\sigma=561(\mathrm{MPa})$

$$
\begin{aligned}
& N_{f}=7.73 \times 10^{7} \\
& \sqrt{\text { area }}=28(\mu \mathrm{m}) \\
& \sqrt{\text { area }} \text { ODA }=53(\mu \mathrm{m})
\end{aligned}
$$

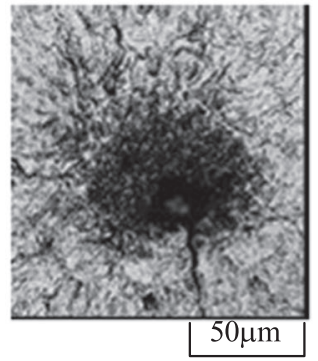

(d) $\sigma=560(\mathrm{MPa})$

$N_{f}=2.17 \times 10^{8}$

$\sqrt{\text { area }}=16(\mu \mathrm{m})$

$\sqrt{\text { area }}$ ODA $=57(\mu \mathrm{m})$

Fig. 2 Optical micrographs of fatigue fracture origin and the optically dark area (ODA) (Specimen QT of JIS-SCM435, $C_{\mathrm{H}}=0.7-0.9$ ppm) [2]. 


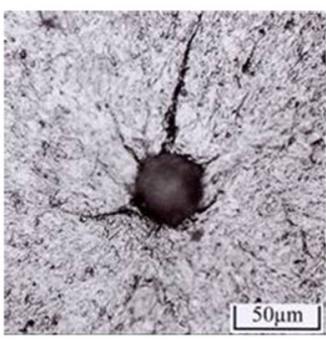

(a) $\sigma=702(\mathrm{MPa})$

$$
\begin{gathered}
N_{f}=5.83 \times 10^{6} \\
\sqrt{\text { area }}=35(\mu \mathrm{m}) \\
\sqrt{\text { area }} \text { ODA }=40(\mu \mathrm{m})
\end{gathered}
$$

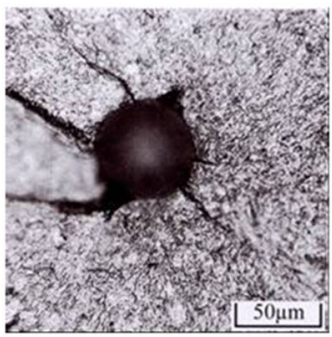

(b) $\sigma=600(\mathrm{MPa})$

$$
N_{f}=1.43 \times 10^{7}
$$$$
\sqrt{\text { area }}=56(\mu \mathrm{m})
$$$$
\sqrt{\text { area }} \text { ODA }=68(\mu \mathrm{m})
$$

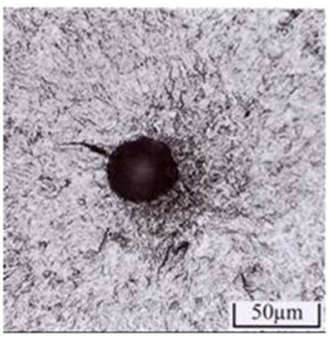

(c) $\sigma=540(\mathrm{MPa})$

$$
\begin{gathered}
N_{f}=4.97 \times 10^{8} \\
\sqrt{\text { area }}=35(\mu \mathrm{m}) \\
\sqrt{\text { area }}_{\text {ODA }}=61(\mu \mathrm{m})
\end{gathered}
$$

Fig. 3 Optical micrographs of fatigue fracture origin and the optically dark area (ODA) (Specimen VQ of JIS-SCM435, $C_{\mathrm{H}}=0.01 \mathrm{ppm}$ ) [5].

identical $N_{\mathrm{f}}$ value. This provides evidence that hydrogen content is closely related to the formation of the ODA.

4 According to scanning electron microscopy observations, ${ }^{22}$ ODAs have a rough morphology quite different from that of the surrounding white areas (Fig. 4). Observations of ODAs by atomic force microscopy and laser microscopy also revealed that the ODA morphology is very different from a typical fatigue fracture surface. $^{22}$

5 Non-metallic inclusions tend to strongly trap hydrogen. ${ }^{28}$ Figure 5 shows the secondary ion images of hydrogen, as trapped by an inclusion at the fracture origin of the JISSCM435 specimens, QT ( $C_{\mathrm{H}}=0.7-0.9$ mass $\left.\mathrm{ppm}\right)$ and VQ $\left(C_{\mathrm{H}}=\sim 0.01\right.$ mass ppm). ${ }^{5}$ Hydrogen is trapped by the inclusion in the QT specimen, whereas almost no hydrogen is trapped by the inclusion in the VQ specimen. The result infers that the dissimilarity in the ODA size of these two specimens is caused by the difference in the amount of hydrogen trapped by the inclusions.

Based on the previously mentioned findings, Murakami et al. proposed a model for the VHCF failure of high-strength steels. ${ }^{2}$ Figure 6 shows a schematic of the mechanism for elimination of the conventional fatigue limit. ${ }^{2}$ According to the model, the growth of the ODA is not due to cycle-bycycle fatigue mechanisms but to a synergistic effect, which combines both the cyclic stress and the hydrogen trapped by the inclusions. Most of the fatigue life is spent in forming the ODA in the VHCF regime. Once the size of the ODA becomes critical, the fatigue crack can only propagate via cyclic stress, without any assistance from the hydrogen.

\section{Optically dark area master curve}

Figures 7 and 8 show the relationship between the size of the ODA, relative to the original inclusion size and the loading cycles to failure, $N_{\mathrm{f}}$, in the Cr-Mo steel and bearing steels. ${ }^{3,9,29}$ Here, the inclusion and ODA sizes are defined by the square root of the area, $\sqrt{\text { area }}$, where area denotes the area of the domain defined by projection of the inclusion on a plane normal to the loading axis. ${ }^{30}$ These monotonically-increasing relationships between $\sqrt{\text { area }_{\mathrm{ODA}}} / \sqrt{\text { area }}$ and $N_{\mathrm{f}}$ are labelled as the 'ODA master curve', where $\sqrt{\text { area }}_{\mathrm{ODA}}$ is a function of the applied stress. ${ }^{29}$ As is schematically presented in Fig. 9, specimens

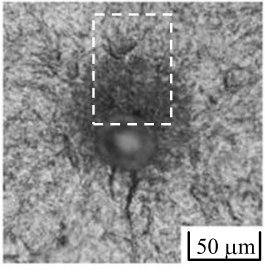

(a) Observed area

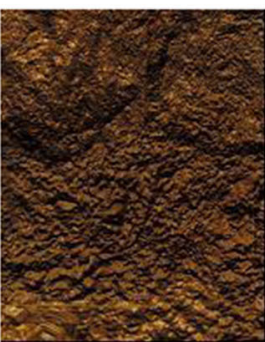

$10 \mu \mathrm{m}$

(b) AFM image

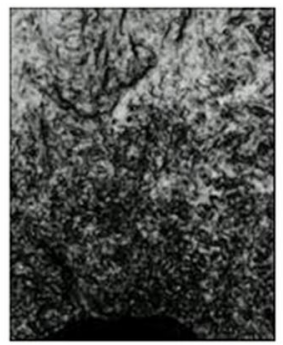

(c) Laser microscope

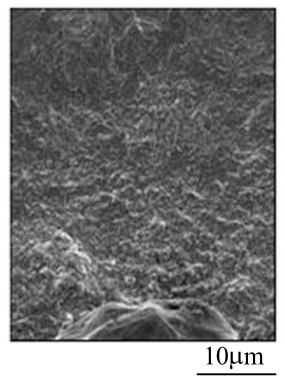

(d) Image by SEM with a high resolution

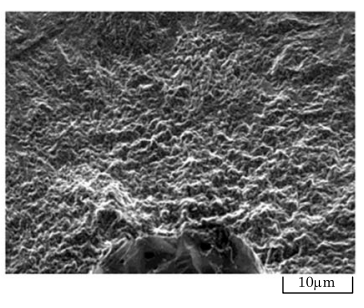

(e) Image by SEM with a high resolution by tilting the specimen

Fig. 4 Images of the optically dark area obtained by using different types of microscopes $\left(\sigma=560 \mathrm{MPa}, N_{\mathrm{f}}=1.11 \times 10^{8}, \sqrt{\text { area }}=29 \mu \mathrm{m}\right.$, $\left.\sqrt{\text { area }}_{\mathrm{ODA}}=55 \mu \mathrm{m}\right)[22]$. AFM, atomic force microscopy; SEM, scanning electron microscopy. 


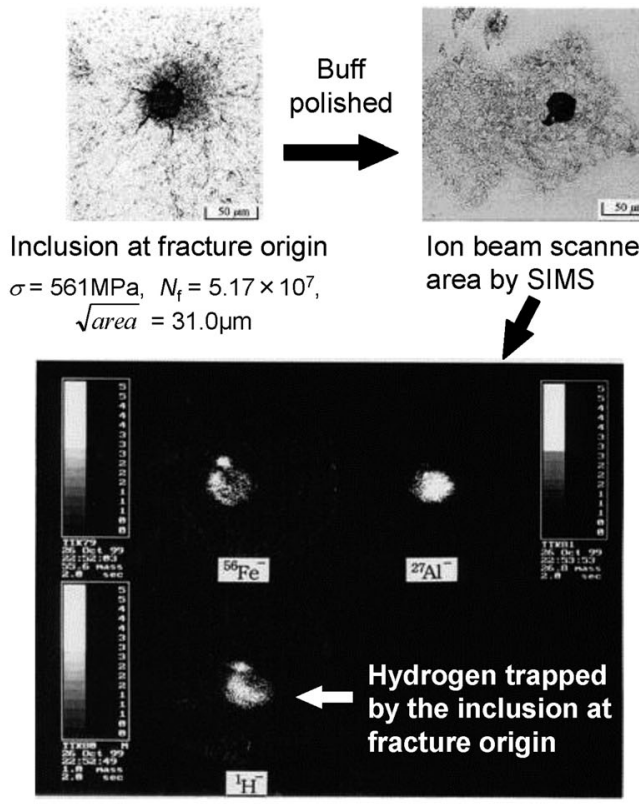

Secondary ion image by SIMS

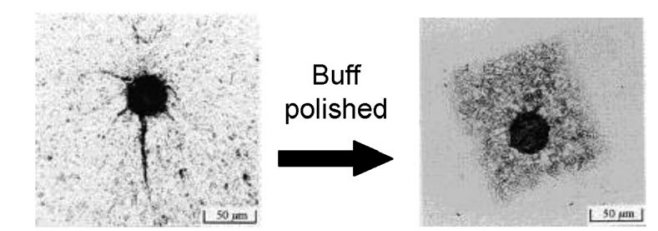

Inclusion at fracture origin $\sigma=702 \mathrm{MPa}, N_{\mathrm{f}}=5.83 \times 10^{6}$ $\sqrt{\text { area }}=35.4 \mu \mathrm{m}$ Ion beam scanned area by SIMS

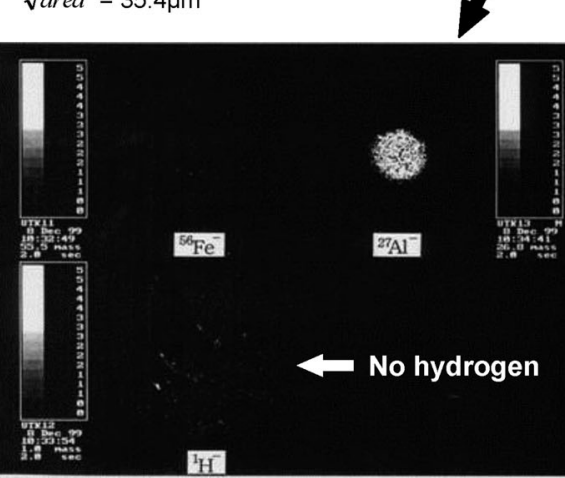

Secondary ion image by SIMS

Fig. 5 Secondary ion images of hydrogen in the vicinity of the inclusion $\left(\mathrm{Al}_{2} \mathrm{O}_{3}(\mathrm{CaO})_{\mathrm{x}}\right)$ at fracture origin in specimens QT and VQ (JISSCM435) [5].

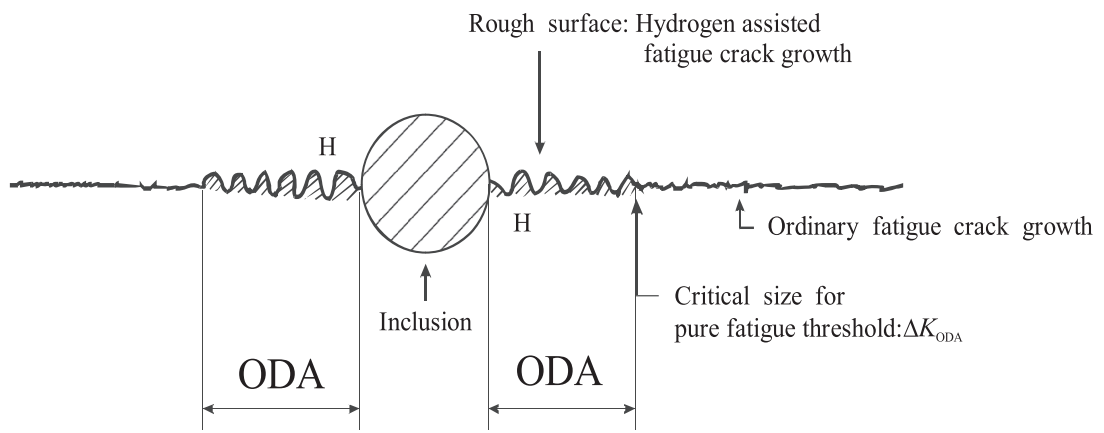

Fig. 6 Mechanism for elimination of the conventional fatigue limit in the very-high-cycle fatigue regime [2]. ODA, optically dark area.

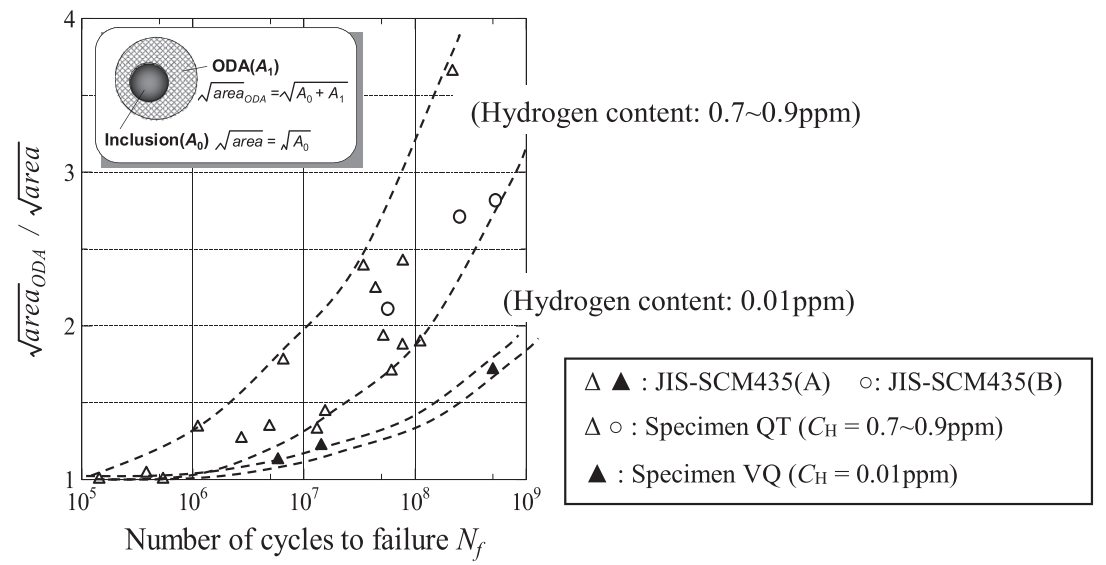

Fig. 7 Master curve of the optically dark area (ODA) for the Cr-Mo steel, JIS-SCM435 [3]. 


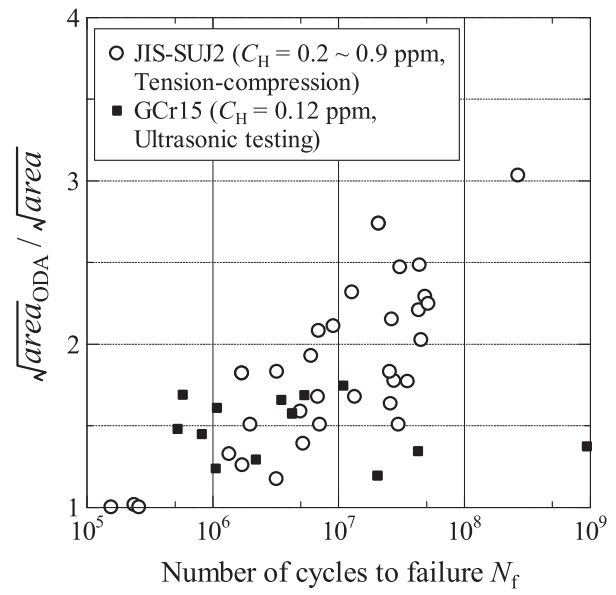

Fig. 8 Master curve of the optically dark area (ODA) for bearing steels $[3,9]$.

having longer fatigue lives, $N_{\mathrm{f}}$, show a larger ODA relative to the original inclusion size, as incorporated in the $\sqrt{\text { area }}$ parameter. Figures 7 and 8 reveal that the master curve for the VQ $\left(C_{\mathrm{H}}=\sim 0.01\right.$ mass $\left.\mathrm{ppm}\right)$ specimens is lower than that for the QT $\left(C_{\mathrm{H}}=0.7-0.9\right.$ mass $\left.\mathrm{ppm}\right)$ specimens.

With knowledge of the master curve, the service loading cycles, $N_{\mathrm{f}}$, for failed components can be estimated. Figure 10 shows an example of the fracture surface of a gear steel. Based on the master curve in Fig. 7, $N_{\mathrm{f}}$ is estimated to be $N_{\mathrm{f}} \approx 5 \times 10^{6}$ from the value of $\sqrt{\text { area }}_{\mathrm{ODA}}$ ' $\sqrt{\text { area }}=1.48$ in Fig. 10. Such a rough estimation is possible for various steels, becasue the ODA master curve for steels subjected to ordinary heat treatment remains unaffected by any variation in the types of steel.

\section{Statistical aspect of the fatigue strength of high-strength steels}

The scatter of the $S-N$ data (e.g. Fig. 1 ) is caused mainly by the large scatter of the inclusion size, because the maximum inclusion contained in the specimen becomes the origin of fracture. ${ }^{30}$ With an increase in component size and the number of components produced, the lower bound of fatigue strength scatter decreases, because of the possibility of the existence of larger inclusions. Figure 1 presents such an example. Thus, the size effect due to the statistical distribution of inclusions should be considered for the evaluation of fatigue strength.

In order to predict the maximum inclusion size contained in a large number of components, the inclusion rating making use of the statistics of extremes is available. The detailed theory and procedures are explained in the existing literature..$^{30-32}$ The essence of the method of statistics of extremes is summarized as follows:

1 The $\sqrt{\text { area }}$ is used as the representative dimension for inclusions. ${ }^{30}$ The maximum size of $\sqrt{\text { area }}$ and $\sqrt{\text { area }}_{\text {max } j}$ is sampled for a standard inspection area, $S_{0}$ (e.g. micrographs of the mirror-finished area), or for a standard inspection volume, $V_{0}$ (e.g. control volume of a fatigue test specimen). This operation is repeated $n$ times and the values of $\sqrt{a r e a}_{\max , j}$ are classified as $\sqrt{\text { area }}_{\text {max }, 1} \leq \sqrt{\operatorname{area}}_{\max , 2} \leq \cdots \leq \sqrt{\operatorname{area}}_{\max , j}$. The cumulative distribution function $F_{\mathrm{j}}(\%)$ and the $j_{\text {th }}$ reduced variates, $y_{\mathrm{j}}$, are then calculated by using the following equations:

$F_{\mathrm{j}}=j \times 100 /(n+1)(\%)$

$y_{\mathrm{j}}=-\ln \{-\ln [j /(n+1)]\}$

2 The data are then plotted on a graph for extreme value distribution. The examples are provided in Fig. 11. Point $j$ has an abscissa co-ordinate of $\sqrt{\text { area }}_{\text {max }, j}$, while the ordinate axis represents either $F_{\mathrm{j}}$ or $y_{\mathrm{j}}$.

3 The reduced variates plotted against $\sqrt{\text { area }}_{\text {max } . j}$ result in a straight line. The linear distribution of the maximum size of inclusions can be expressed as

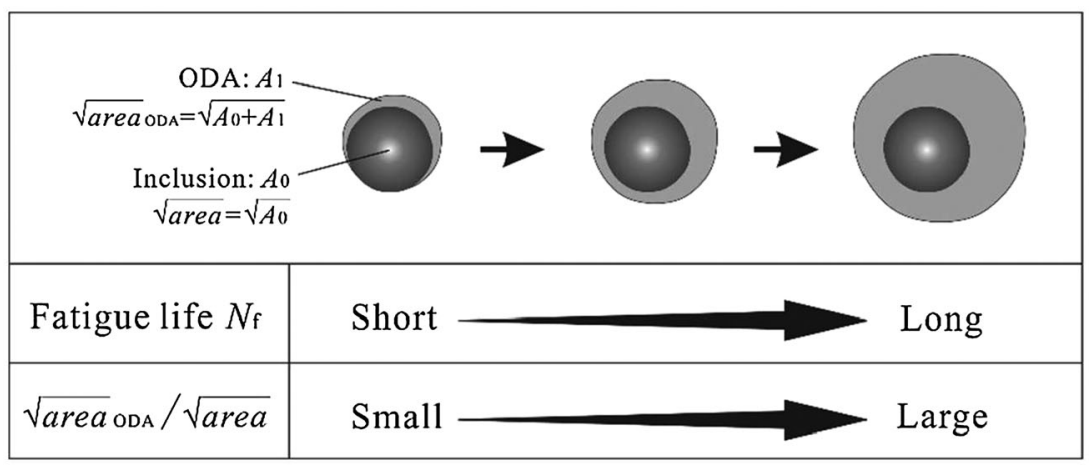

Fig. 9 Increase in the optically dark area (ODA) size, $\sqrt{\text { area }}_{\mathrm{ODA}}$, relative to the original inclusion size, $\sqrt{\text { area }}$, with an increase in fatigue life, $N_{\mathrm{f}}$. 

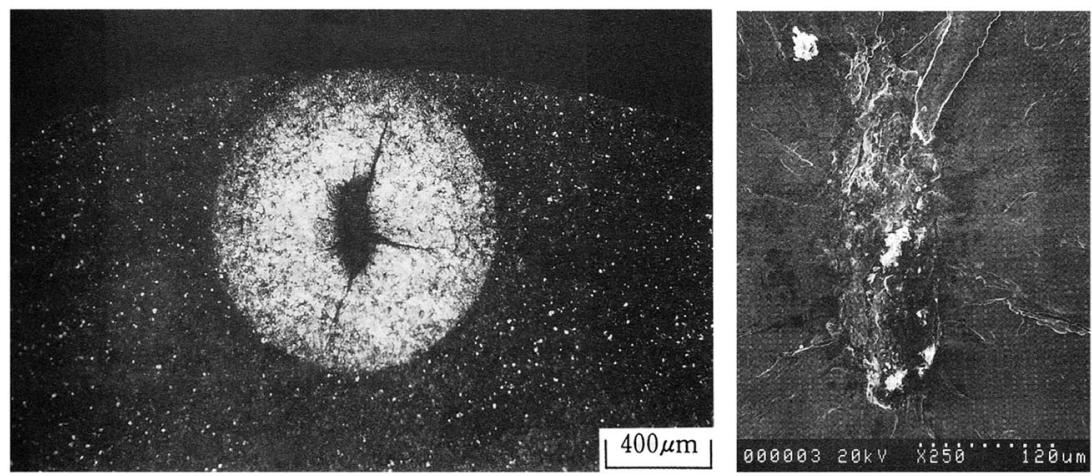

Fig. 10 Fatigue fracture surface of a gear steel (Inclusion size: $\sqrt{\text { area }}=162 \mu \mathrm{m}$, optically dark area (ODA) size: $\sqrt{\text { area }}_{\mathrm{ODA}}=240 \mu \mathrm{m}, \sqrt{\text { area }}_{\mathrm{ODA}}$ ' $\sqrt{\text { area }}=1.48$. Estimated fatigue life: $N_{\mathrm{f}} \cong 5 \times 10^{6}$ ).

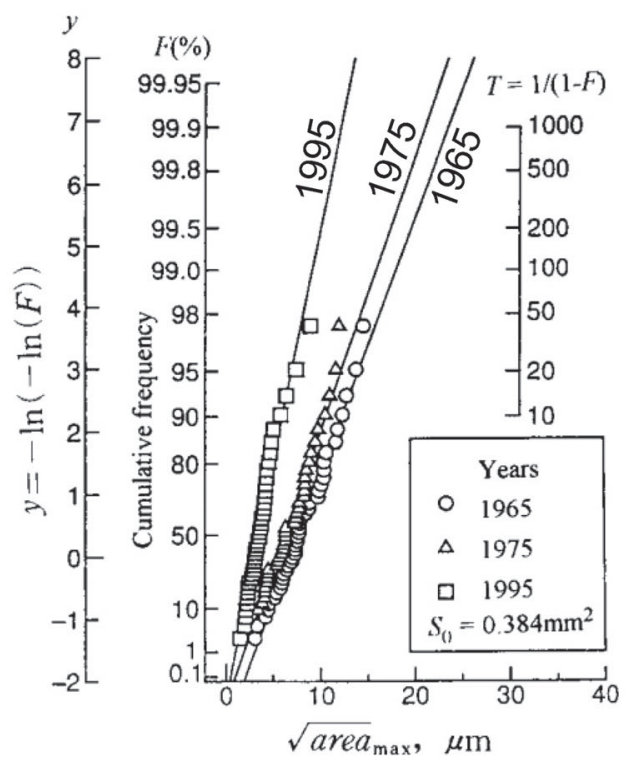

(a) Improvements in the quality of JIS-SUJ2 by production years [30]

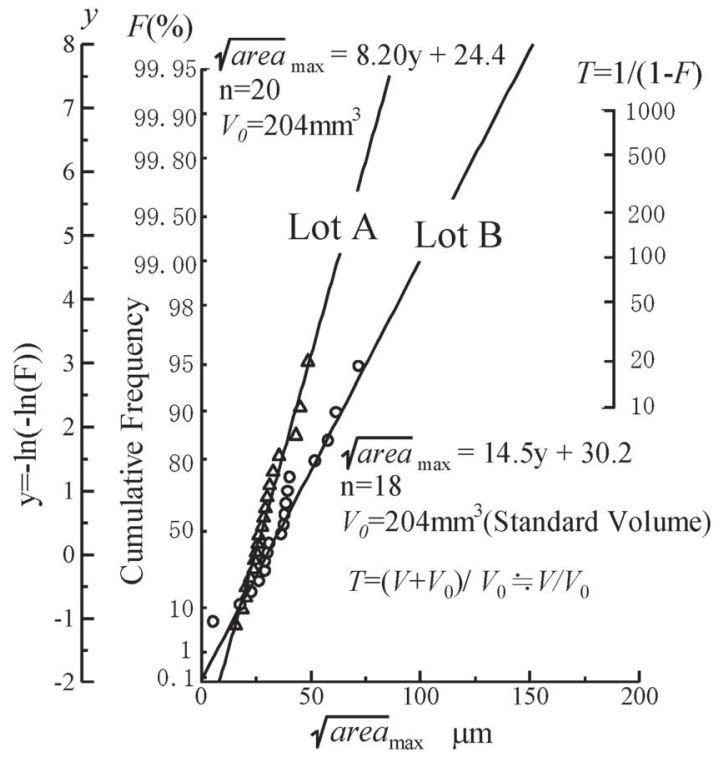

(b) Differences in the quality of SCM 435 by companies and lots

Fig. 11 Examples of the extreme value distributions of inclusion size.

$$
\sqrt{\text { area }}_{\max }=a \cdot y+b
$$

where, $a$ and $b$ are constants, $y=-\ln \{-\ln [j /(n+1)]\}$ and $T=S / S_{0}\left(\right.$ or $\left.T=V / V_{0}\right)$. Here, $T$ represents the return period, and $S$ (or $V$ ), the area (or volume) for the prediction. From Eq. (3), the maximum inclusion size, $\sqrt{\text { area }}_{\max }$, can be obtained for an identical $S$ or $V$.

The estimated $\sqrt{\text { area }}_{\text {max }}$ is not only useful for the prediction of fatigue strength scatter bands for large numbers of specimens or mass production products but also for the quality control of materials at the purchase-acceptance stage. Over the course of decades, continual improvement in steel-making technology has increased steel cleanliness, leading to a remarkable decrease in the size of non-metallic inclusions in various steels. The fatigue strength of highstrength steels tends to increase year by year, corresponding to the reduction of inclusion sizes (Fig. 11(a) ${ }^{30}$ ). Nevertheless, even nowadays, very rare large inclusions still cause fatigue failure at around the lower band of statistical scatter for fatigue strength in most high-strength steels.

\section{Threshold stress intensity factor range $\Delta K_{\text {th }}$ for opti- cally dark area}

As is well-known, a small crack (e.g. a crack smaller than $1 \mathrm{~mm}$ ) grows much faster than a large or long crack (e.g. a crack in a compact-tension specimen), when the growth 

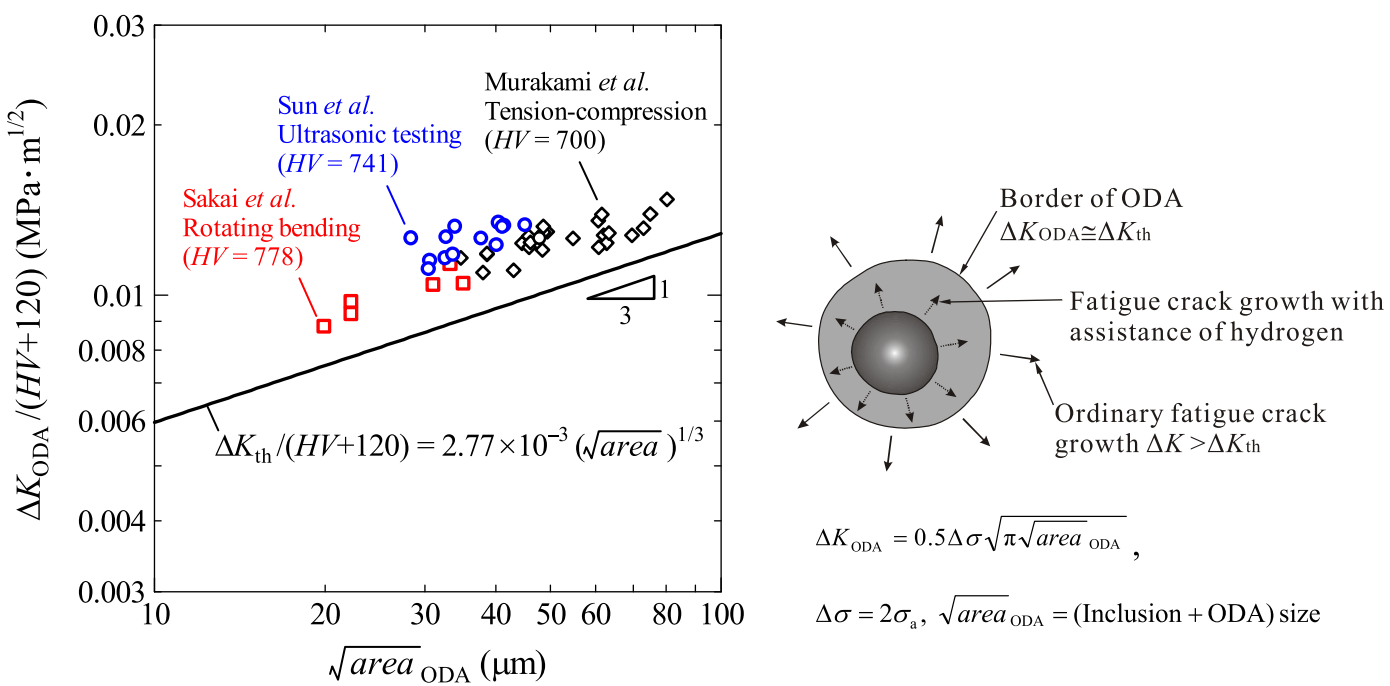

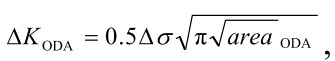$$
\Delta \sigma=2 \sigma_{\mathrm{a}}, \sqrt{\text { area }}_{\mathrm{ODA}}=(\text { Inclusion }+ \text { ODA }) \text { size }
$$

Fig. 12 Relationship between $\sqrt{\text { area }}_{\mathrm{ODA}}$ and $\Delta K_{\mathrm{ODA}}$ for bearing steels $[6,9,17]$. ODA, optically dark area.

rates are compared at the same $\Delta K$ level. ${ }^{33-35}$ Moreover, it has also been reported that the threshold stress intensity factor range, $\Delta K_{\mathrm{th}}$, for the small crack is smaller than that of the large or long crack, that is, the value of $\Delta K_{\text {th }}$ is not a material constant, but it decreases by decreasing the crack size in the small crack regime. ${ }^{36-41}$ Accordingly, crack initiation from non-metallic inclusions, as well as subsequent growth, should be dealt with the theory of small cracks. As has been discussed previously, it is presumed that the border of ODAs is the transition point between two fracture mechanisms, that is, hydrogen-assisted fatigue fracture and the start of the ordinary fatigue crack growth.

Figure 12 shows the relationship between the ODA size, $\left(\sqrt{\text { area }}_{\mathrm{ODA}}\right)$, and the stress intensity factor range at the periphery of the ODA $\left(\Delta K_{\mathrm{ODA}}\right)$ for bearing steels (JIS-SUJ2 and GCr15). ${ }^{6,9,17}$ It must be noted that, in the ordinate of Fig. $12, \Delta K_{\mathrm{ODA}}$ is normalized by $(H V+120)$, in order to compare the experimental data of steels with different hardnesses. The values of $\Delta K_{\mathrm{ODA}}$ were calculated based on the following equation, proposed by Murakami et al.: ${ }^{30}$

$\Delta K_{\mathrm{ODA}}=0.5 \Delta \sigma \sqrt{\pi \sqrt{\text { area }}_{\mathrm{ODA}}}($ For an internal crack)

where $\Delta K_{\mathrm{ODA}}: \mathrm{MPa} \sqrt{\mathrm{m}}, \Delta \sigma: \mathrm{MPa}, \sqrt{\text { area }}_{\mathrm{ODA}}: \mu \mathrm{m}$. The values of $\Delta K_{\mathrm{ODA}}$, obtained by different test methods (i.e. tension-compression, rotating bending and ultrasonic testing), are nearly proportional to $\left(\sqrt{\text { area }}_{\mathrm{ODA}}\right)^{1 / 3}$ in the range of $\sqrt{\text { area }}_{\mathrm{ODA}}=20-100 \mu \mathrm{m}$ and are slightly higher than the prediction proffered by the $\sqrt{\text { area }}$ parameter model $\mathrm{l}^{30,40,41}$ (the solid line in Fig. 12), which is expressed as follows:

$\Delta K_{\mathrm{th}}=2.77 \times 10^{-3}(H V+120)\left(\sqrt{\operatorname{area}}_{\mathrm{ODA}}\right)^{1 / 3}$

where $\Delta K_{\mathrm{th}}: \mathrm{MPa} \sqrt{\mathrm{m}}, \sqrt{\text { area }}_{\mathrm{ODA}}: \mu \mathrm{m}$ and $H V: \mathrm{kgf} / \mathrm{mm}^{2}$.
The aforementioned results evidently present the behaviour of the ODA crack as that of a small crack, thereby indirectly supporting the proposed model in Fig. 6 for the VHCF failure. After very slow fatigue crack growth inside the ODA near the inclusion, ${ }^{4}$ the crack size exceeds the critical dimension for the mechanical threshold value, $\Delta K_{\mathrm{th}}$, as estimated by the $\sqrt{\text { area }}$ parameter model, and then the fatigue crack continues to grow by ordinary fatigue crack propagation mechanisms, without any hydrogen assistance.

Figure 13 shows modified $S-N$ data for JISSCM 435, that is, the relationship between the number of loading cycles to failure, $N_{\mathrm{f}}$, and the ratio of applied stress, $\sigma$, to the modified threshold stress, $\sigma_{\mathrm{w}}{ }^{\prime}$, calculated by considering the ODA size instead of using

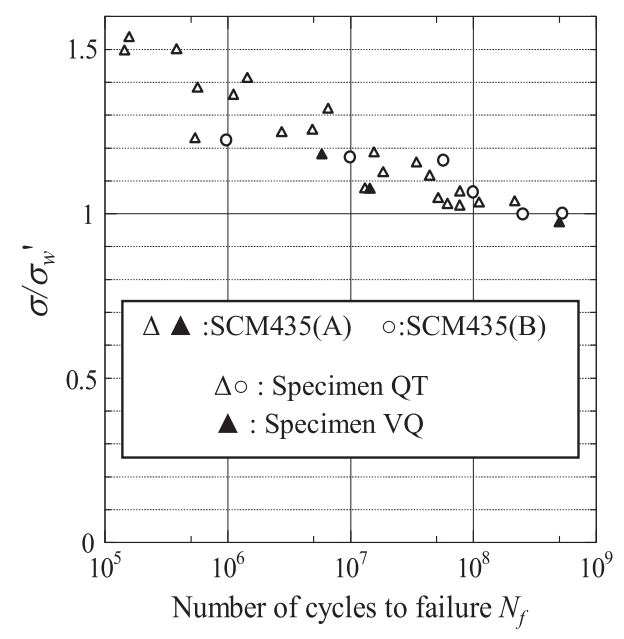

Fig. 13 Modified $S-N$ data for JIS SCM435 $\left(\sigma_{\mathrm{w}}{ }^{\prime}\right.$ : modified fatigue limit for a small crack in the optically dark area, Eq. (6)) [3]. 
the original inclusion size, $\sqrt{\text { area. }}{ }^{5}$ The value of $\sigma_{\mathrm{w}}{ }^{\prime}$ for the stress ratio, $R=-1$ can be calculated by the following equation: $:^{2,5}$

$\sigma_{\mathrm{w}}{ }^{\prime}=1.56(H V+120) /\left(\sqrt{\text { area }}_{\mathrm{ODA}}\right)^{1 / 6}$

In all cases, the values of $\sigma / \sigma_{\mathrm{w}}{ }^{\prime}$ for failed specimens exceed approximately 1.0. This indicates that $\sigma_{\mathrm{w}}{ }^{\prime}$ is the threshold stress, and $\Delta K_{\mathrm{ODA}}$ is the threshold stress intensity factor range for the small ODA crack. The results shown in Fig. 13 also support the proposed model in Fig. 6 for the VHCF failure.

\section{FATIGUE DESIGN METHOD FOR VERY-HIGH-CYCLE FATIGUE LIFE REGIME}

Because the conventional fatigue limit disappears in high-strength steels, new fatigue design methods should be developed based on the service life of components. Introducing the so-called empirical 'safety factor' to this problem is not recommended because the fatigue strength and life of components decrease with increasing size and number of products, because of the statistical distribution of the size of non-metallic inclusions. No 'conservative constant safety factor' can be determined for this problem.
The necessary data for the design are listed as follows:

(i) the ODA master curve as a function of fatigue life, $N_{\mathrm{f}}$ (Figs. 7 and 8);

(ii) prediction of the maximum inclusion size, $\sqrt{\text { area }}_{\max }$, by statistics of extremes (Fig. 11); and

(iii) determination of the threshold stress (allowable design stress) for the critical ODA size, based on the $\sqrt{\text { area }}$ parameter model. ${ }^{30}$

The allowable design stress, $\sigma_{\text {allowable, }}$ for a given design life, $N_{\mathrm{fD}}$, can be predicted as follows. Figure 14 presents the flowchart of the VHCF life design method. Figure 15 illustrates an example of the application of the method to JIS-SCM435 steel.

The design procedure:

1 Determination of the design life, $N_{\mathrm{fD}}$, for the component in question (e.g. under $R=-1$ ).

2 Determination of the ODA growth, relative to the original inclusion size, $\gamma=\sqrt{\text { area }}_{\mathrm{ODA}} / \sqrt{\text { area }}_{\max }$, corresponding to $N_{\mathrm{fD}}$ from the ODA master curve (e.g. Figs. 7 and 8), where, $\sqrt{\text { area }}_{\max }$ is the maximum inclusion size expected to occur in the entire set of components to be produced.

3 Determination of the expected maximum size of inclusions, $\sqrt{\text { area }}_{\text {max }}$, by using the statistics of extremes (e.g. Fig. 11) for a given return period, $T$. $\left(T=V / V_{0}\right.$, where $V$ is the total amount of control volume in the

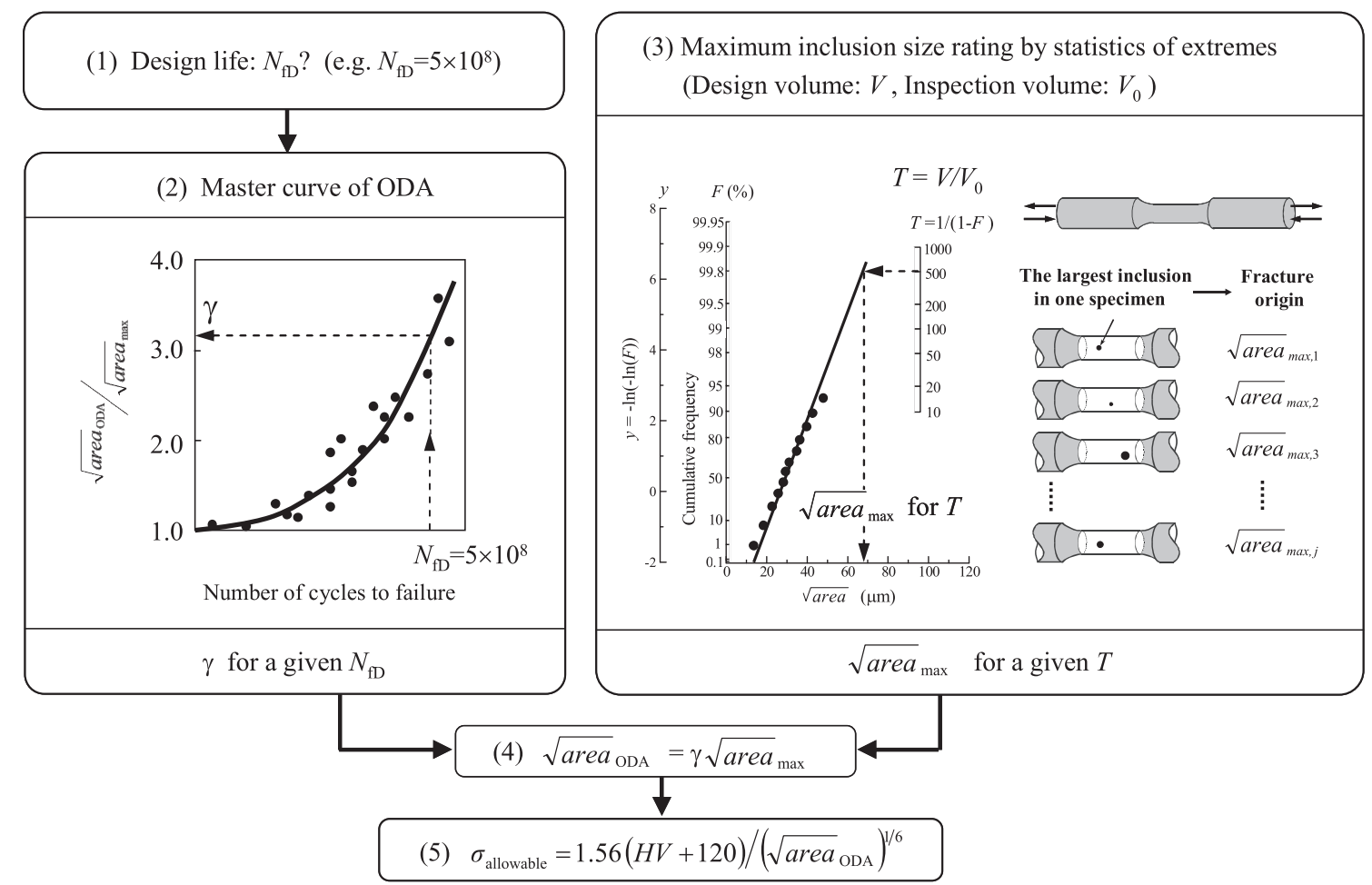

Fig. 14 Flowchart for the very-high-cycle fatigue life design method. ODA, optically dark area. 


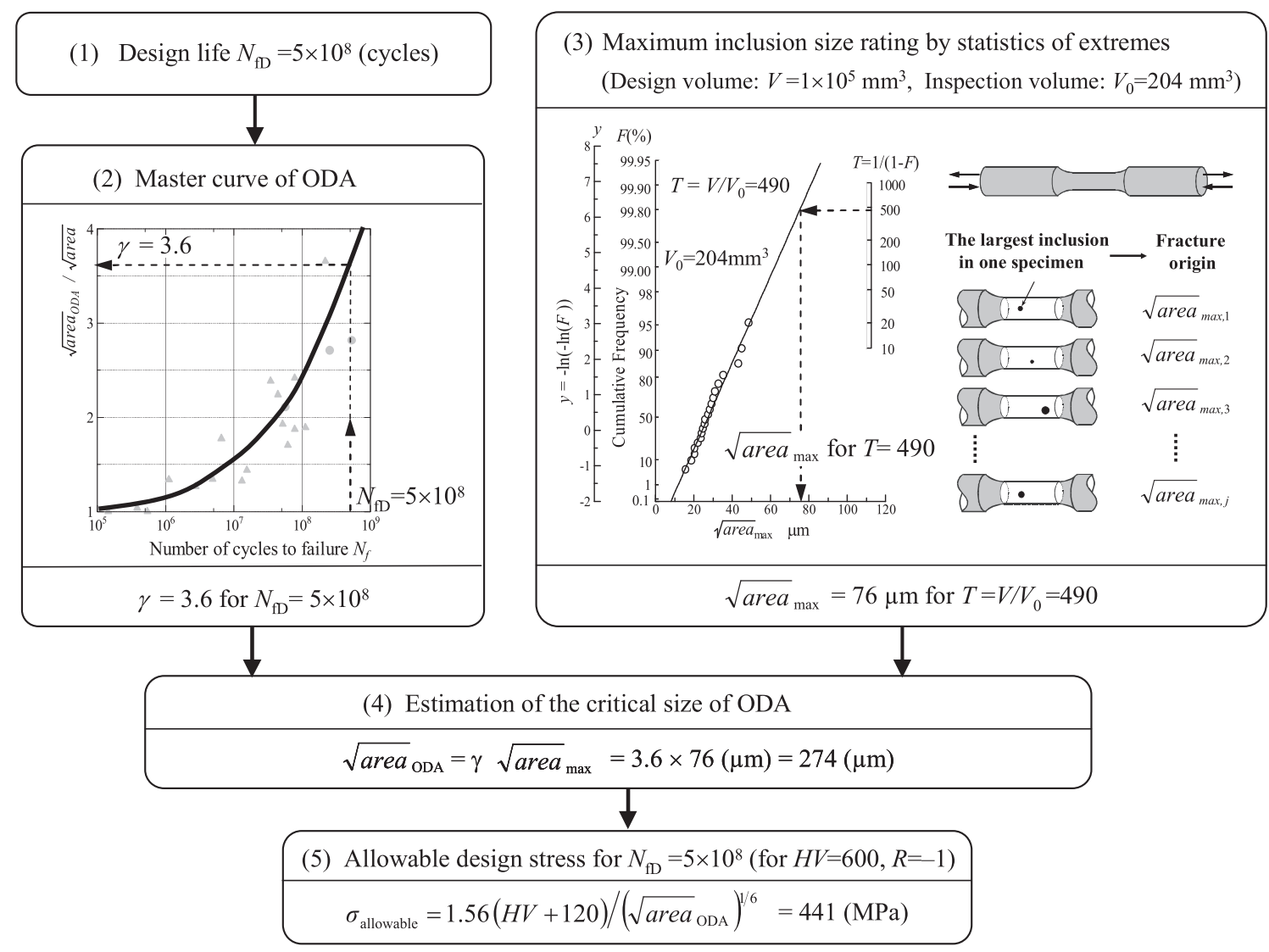

Fig. 15 Example of the VHCF-life design for JIS SCM435 (Design life: $N_{\mathrm{fD}}=5 \times 10^{8}$, design volume: $V=1 \times 10^{5} \mathrm{~mm}^{3}$ ). ODA, optically dark area.

components put into service and $V_{0}$ is the unit inspection volume used for the sample)

4 From (2) and (3), the critical ODA size, $\sqrt{\text { area }}_{\mathrm{ODA}}$ by $\sqrt{\text { area }}$ ODA $=\gamma \sqrt{\text { area }}_{\text {max }}$, can be obtained, where $\gamma$ is the growth ratio up to $N=N_{\mathrm{fD}}$.

5 Substitution of $\sqrt{\text { area }}_{\mathrm{ODA}}$ in Eq. (6): $\sigma_{\text {allowable }}=1.56$ $(H V+120) /\left(\sqrt{\text { area }}_{\mathrm{ODA}}\right)^{1 / 6}$.

The obtained $\sigma_{\text {allowable }}$ is the allowable stress at the lower bound of fatigue strength scatter for the components in question during the expected service life, $N=N_{\mathrm{fD}}$. In fact, the proposed design method has successfully been applied to the development of a half-toroidal-type transmission, CVT, for automobiles. ${ }^{42}$

\section{CONCLUSIONS}

The factors affecting the fatigue failure of high-strength steels in the VHCF regime are reviewed, and the mechanism for the non-existence of the conventional fatigue limit is discussed. It is suggested that during the evaluation of the fatigue strength of high-strength steels, the following factors should be considered: (i) the growth rule of ODAs with the assistance of internal hydrogen;

(ii) the difference in threshold stress intensity factor range, $\Delta K_{\text {th }}$, between small cracks and large cracks; and

(iii) the statistical aspect of fatigue strength, as influenced by inclusion size.

In consideration of all the various factors, a new fatigue design method has been proposed for the VHCF regime. The design method incorporates the allowable

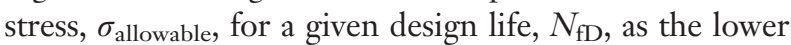
boundary of fatigue strength scatter due to the number of components produced. The proposed method has already been successfully applied during the development of an automobile component.

\section{REFERENCES}

1 Murakami, Y., Ueda, T., Nomoto, T. and Murakami, Y. (1998) Proceeding of the 24th Symposium on Fatigue, Soc. Mater. Sic., Japan 47-50.

2 Murakami, Y., Nomoto, T. and Ueda, T. (1999) Factors influencing the mechanism of superlong fatigue failure in steels. Fatigue Fract. Eng. Mater. Struct., 22, 581-590. 
3 Murakami, Y., Nomoto, T., Ueda, T. and Murakami, Y. (2000) On the mechanism of fatigue failure in the superlong life regime ( $N>10^{7}$ cycles). Part 1 : influence of hydrogen trapped by inclusions. Fatigue Fract. Eng. Mater. Struct., 23, 893-902.

4 Murakami, Y., Nomoto, T., Ueda, T. and Murakami, Y. (2000) On the mechanism of fatigue failure in the superlong life regime ( $N>10^{7}$ cycles). Part II: influence of hydrogen trapped by inclusions. Fatigue Fract. Eng. Mater. Struct., 23, 903-910.

5 Murakami, Y., Konishi, H., Takai, K. and Murakami, Y. (2000) Acceleration of superlong fatigue failure by hydrogen trapped by inclusions and elimination of conventional fatigue limit. Tetsuto-Hagane, 86, 777-783.

6 Murakami, Y., Yokoyama, N. N. and Nagata, J. (2002) Mechanism of fatigue failure in ultralong life regime. Fatigue Fract. Eng. Mater. Struct., 25, 735-746.

7 Murakami, Y. and Nagata, J. (2005) Influence factors of fatigue design in ultralong life regime and effect of hydrogen on fatigue strength of high strength steel. Trans. Fpn. Soc. Mech. Eng., Ser. A, 70, 1093-1101.

8 Murakami, Y. and Nagata, J. (2005) Effect of hydrogen on high cycle fatigue failure of high strength steel, SCM435. F. Soc. Mater. Sci., 7pn, 54, 420-427.

9 Sun, C., Xie, J., Zhao, A., Lei, Z. and Hong, Y. (2012) A cumulative damage model for fatigue life estimation of high-strength steels in high-cycle and very-high-cycle fatigue regimes. Fatigue Fract. Eng. Mater. Struct., 35, 638-647.

10 Sun, C., Lei, Z., Xie, J. and Hong, Y. (2013) Effects of inclusion size and stress ratio on fatigue strength for high-strength steels with fish-eye mode failure. Int. F. Fatigue, 48, 19-27.

11 Lei, Z., Hong, Y., Xie, J., Sun, C. and Zhao, A. (2012) Effects of inclusion size and location on very-high-cycle fatigue behavior for high strength steels. Mater. Sci. Eng. A, 558, 234-241.

12 Qian, G., Hong, Y. and Zhou, C. (2010) Investigation of high cycle and very-high-cycle fatigue behaviors for a structural steel with smooth and notched specimens. Eng. Fail. Anal., 17, 1517-1525.

13 Zhao, A., Xie, J., Sun, C., Lei, Z. and Hong, Y. (2011) Prediction of threshold value for FGA formation. Mater. Sci. Eng. A, 528, 6872-6877.

14 Qian, G., Zhou, C. and Hong, Y. (2011) Experimental and theoretical investigation of environmental media on very-highcycle fatigue behavior for a structural steel. Acta Mater., 59, $1321-1327$

15 Zhao, A., Xie, J., Sun, C., Lei, Z. and Hong, Y. (2012) Effects of strength level and loading frequency on very-high-cycle fatigue behavior for a bearing steel. Int. 7. Fatigue, 38, 46-56.

16 Hong, Y., Zhao, A., Qian, G. and Zhou, C. (2012) Fatigue strength and crack initiation mechanism of very-high-cycle fatigue for low alloy steels. Metall. Mater. Trans. A, 43A, 2753-2762.

17 Sakai, T., Takeda, M., Shiozawa, K., Ochi, Y., Nakajima, M., Nakamura, M. and Oguma, N. (2000) Experimental reconfirmation of characteristic S-N property for high carbon chromium bearing steel in wide life region in rotating bending. 7. Soc. $M a-$ ter. Sci. 7pn., 49, 779-785.

18 Abe, T., Furuya, Y. and Matsuoka, S. (2001) Giga-cycle fatigue properties for $1800 \mathrm{MPa}$-class spring steels. Trans. Zpn. Soc. Mech. Eng., Ser. A, 67, 1988-1995.

19 Furuya, Y., Abe, T. and Matsuoka, S. (2003) $10^{10}$-cycle fatigue properties of $1800 \mathrm{MPa}$-class JIS-SUP7 spring steel. Fatigue Fract. Eng. Mater. Struct., 26, 641-645.

20 Naito, T., Ueda, H. and Kikuchi, M. (1984) Fatigue behavior of carburized steel with internal oxides and nonmartensitic microstructure near the surface. Metall. Trans., 15A, 1431-1436.

21 Emura, H. and Asami, K. (1989) Fatigue strength characteristics of high strength steel. Trans. Fpn. Soc. Mech. Eng., Ser. A, 55, 45-50.
22 Ueda, T. and Murakami, T. (2003) Effect of hydrogen on ultralong life fatigue failure of a high strength steel and fracture morphology of ODA. Trans. Fpn. Soc. Mech. Eng., Ser. A, 69, 908-915.

23 Huang, Z. Y., Wang, Q. Y., Wagner, D., Bathias, C. and Chaboche, J. L. (2013) A rapid scatter prediction method for very high cycle fatigue. Fatigue Fract. Eng. Mater. Struct., 36, 462-468.

24 Schuller, R., Fitzka, M., Irrasch, D., Tran, D., Pennings B. and Mayer, H. (2015) VHCF properties of nitrided $18 \mathrm{Ni}$ maraging steel thin sheets with different Co and Ti content. Fatigue Fract. Eng. Mater. Struct., 38, 518-527.

25 Suh, M.-S., Suh C.-M. and Pyun, Y.-S. (2013) Very high cycle fatigue characteristics of a chrome-molybdenum steel treated by ultrasonic nanocrystal surface modification technique. Fatigue Fract. Eng. Mater. Struct., 36, 769-778.

26 Khan, M. K., Liu, Y. J., Wang, Q. Y. and Pyoun, Y. S. (2015) Effect of small scale notches on the very high cycle fatigue of AISI 310 stainless steel. Fatigue Fract. Eng. Mater. Struct., 38, 290-299.

27 Murakami, Y., Matsunaga, H., Abyazi, A. and Fukushima, Y. (2013) Defect size dependence on threshold stress intensity for high-strength steel with internal hydrogen. Fatigue Fract. Eng. Mater. Struct., 36, 836-850.

28 Takai, K., Homma, Y., Izutsu, K. and Nagumo, M. (1996) Identification of trapping sites in high-strength steels by secondary ion mass spectrometry for thermally desorbed hydrogen. 7. Jpn. Inst. Met. Mater., 60, 1155-1162.

29 Murakami, Y. and Nagata, J. (2003) Factors influencing the formation of ODA in ultralong fatigue regime. 7. Soc. Mater. Sci., 7pn, 52, 966-973.

30 Murakami, Y. (2002) Metal Fatigue: Effects of Small Defects and Nonmetallic Inclusions. Elsevier Ltd., Oxford.

31 Beretta, S. and Murakami, Y. (1998) Statistical analysis of defects for fatigue strength prediction and quality control of materials. Fatigue Fract. Eng. Mater. Struct., 21, 1049-1065.

32 Beretta S. and Murakami Y. (2001) Largest-extreme-value distribution analysis of multiple inclusion types in determining steel cleanliness. Metall. Trans. B, 32B, 517-523.

33 Miller, K. J. (1982) The short crack problem. Fatigue Fract. Eng. Mater. Struct., 5, 223-232.

34 Suresh, S. and Ritchie R. O. (1984) Propagation of short fatigue cracks. Int. Met. Rev., 29, 445-476.

35 Ritchie, R. O. and Lankford, J. (1986) Small fatigue cracks: a statement of the problem and potential solutions. Mater. Sci. Eng., 84, 11-16.

36 Kitagawa, H. and Takahashi, S. (1979) Fracture mechanical approach to very small fatigue crack growth and to the threshold condition. Trans. Fpn. Soc. Mech. Eng., Ser. A, 45, 1289-1303.

37 Frost, E. N., Pook, P. L. and Denton, K. (1971) A fracture mechanics analysis of fatigue crack growth data for various materials. Eng. Fract. Mech., 3, 109-126.

38 Kobayashi, H. and Nakazawa, H. (1969) The effects of notch depth on the initiation propagation and non-propagation of fatigue cracks. Trans. Jpn. Soc. Mech. Eng., Ser. I, 35, 1856-1863.

39 Kikukawa, M., Jono, M., Tanaka, K. and Takatani, M. (1976) Measurement of fatigue crack propagation and crack closure at low stress intensity level by unloading elastic compliance method. 7. Soc. Mater. Sci. 7pn., 25, 899-903.

40 Murakami, Y. and Endo, M. (1986) Effects of hardness and crack geometry on $\Delta K_{\text {th }}$ of small cracks. F. Soc. Mater. Sci. Fpn., 35, 911-917.

41 Murakami, Y. and Endo, M. (1986) Effects of hardness and crack geometries on $\Delta K_{\text {th }}$ of small cracks emanating from small defects. In: The Behaviour of Short Fatigue Cracks EGF Pub. 1, Eds. (Edited by K. J. Miller and E. R. de los Rios), Mech. Eng. Pub. London, pp. 275-293.

42 Machida, H. and Murakami, Y. (2000) Development of the half toroidal CVT powertoros unit. NSK Tech. 7., 7pn., 669, 9-20. 